\title{
Polarity and energetics of inner core lightning in three intense North Atlantic hurricanes
}

\author{
Jeremy N. Thomas, ${ }^{1,2,3}$ Natalia N. Solorzano, ${ }^{1,3}$ Steven A. Cummer, ${ }^{4}$ \\ and Robert H. Holzworth ${ }^{2}$ \\ Received 14 August 2009; revised 23 October 2009; accepted 30 October 2009; published 12 March 2010.
}

[1] We use the World Wide Lightning Location Network (WWLLN), low-frequency magnetic fields measured at Duke University, and storm intensity data (winds and central pressure) to examine the polarity and energetics of lightning within $100 \mathrm{~km}$ of the centers (inner core regions) of North Atlantic hurricanes Emily, Katrina, and Rita (2005).

WWLLN provides the lightning locations. Polarities, peak currents, and vertical impulse charge moment changes are derived from the Duke magnetic field measurements. In agreement with past studies, we find episodic inner core lightning outbreaks prior to and during most changes in storm intensity. A new result of our analysis indicates an increase in the relative number of positive cloud-to-ground lightning in the inner core prior to and during periods of storm weakening, which is potentially important for hurricane intensity change forecasting. Additionally, we find that the majority of inner core lightning located by WWLLN had peak currents that surpassed the threshold needed to produce optical emissions (elves) and drive electron density perturbations in the lower ionosphere (80-105 km). Since these high peak current lightning occurred in short-duration outbreaks, they had an accumulated effect on the ionospheric electron density, as shown by recent modeling studies. Our results suggest that the inner core lightning in intense hurricanes might be significant drivers of perturbations in the lower ionosphere during these inner core lightning outbreaks.

Citation: Thomas, J. N., N. N. Solorzano, S. A. Cummer, and R. H. Holzworth (2010), Polarity and energetics of inner core lightning in three intense North Atlantic hurricanes, J. Geophys. Res., 115, A00E15, doi:10.1029/2009JA014777.

\section{Introduction}

[2] The intrinsically episodic cloud-to-ground lightning activity in the inner core, which comprises the eyewall and inner rainbands [Willoughby, 1988], has been associated with intensity changes in tropical cyclones in numerous studies. Lyons and Keen [1994] conducted several case studies of the lightning activity associated with North Atlantic basin tropical storms and hurricanes that occurred during the 1983-1984 and 1987-1988 seasons. They found that lightning was common within the outer rainbands of storms, but generally infrequent within the inner core of mature tropical cyclones. Two exceptions were hurricanes Diana (1984) and Florence (1988). In these storms, neareyewall cloud-to-ground (CG) lightning activity preceded

\footnotetext{
${ }^{1}$ Physics Department, Bard High School Early College Queens, Long Island City, New York, USA.

${ }^{2}$ Department of Earth and Space Sciences, University of Washington, Seattle, Washington, USA.

${ }^{3}$ NorthWest Research Associates, Redmond, Washington, USA.

${ }^{4}$ Department of Electrical and Computer Engineering, Duke University, Durham, North Carolina, USA.

Copyright 2010 by the American Geophysical Union. 0148-0227/10/2009JA014777
}

periods of convection intensification. They also reported lightning associated with two large supercells that triggered closed circulation during an unnamed tropical storm in 1987. In a later study using the National Lightning Detection Network (NLDN), Samsury and Orville [1994] investigated lightning activity in hurricanes Hugo and Jerry (1989) during an 18 hour period for each storm that included landfall. They found that Jerry had more than 20 times the number of CG lightning flashes compared with the more intense (stronger winds and lower minimum central pressure) Hugo. Most of this lightning activity was located in the rainband regions and occurred before landfall. These observations of Samsury and Orville suggested that more intense storms do not necessarily produce more lightning. The study found that about $80 \%$ of these lightning were negative CG lightning and had mean peak current magnitudes of 40-65 kA.

[3] Molinari et al. [1994] examined CG lightning activity during Hurricane Andrew (1992) using NLDN data. They reported three distinct regimes concerning the spatial distribution of lightning activity. These three spatial regions are approximately radially distributed, with the following distinctions according to the frequency of lightning occurrence: a weak maximum in lightning activity in the eyewall, a minimum $40-100 \mathrm{~km}$ from the storm center, and a large, broader maximum in the outer rainbands $190 \mathrm{~km}$ from the 
center. As in the case studies of hurricanes Diana (1984) and Florence (1988) [Lyons and Keen, 1994], the eyewall lightning for Andrew occurred prior to or during periods of storm intensification. These eyewall lightning were negative in polarity and occurred in a region of maximum radar reflectivity that was several kilometers inward from the highest eyewall cloud tops. Most of the positive lightning occurred in the stratiform regions, or moat between the eyewall and rainbands. Molinari et al. [1999] found similar lightning activity patterns during nine other North Atlantic basin hurricanes.

[4] Using the satellite-borne Optical Transient Detector (OTD), Cecil and Zipser [1999] found no apparent relationship between lightning activity (cloud-to-ground and in cloud) and tropical cyclone intensity change. However, since OTD is in low Earth orbit, it observed each storm for only several minutes per day. Hence, this lack of correlation is possibly due to the satellite's very low sample rate. OTD did detect inner core lightning activity during periods of intensity change for Hurricane Linda and Typhoon Paka, which were intense tropical cyclones in the Eastern and Western North Pacific during 1997 (see http://thunder.msfc. nasa.gov/bookshelf/docs/white_paper_driscoll.html).

[5] Corbosiero and Molinari [2002] showed a strong correlation between the azimuthal distribution of lightning flashes and the direction of vertical wind shear using NLDN data for 35 North Atlantic basin tropical cyclones. In their analysis, the vertical wind shear was divided into 3 categories: $0-5,5-10$ and $>10 \mathrm{~m} / \mathrm{s}$. When the magnitude of the vertical shear exceeded $5 \mathrm{~m} / \mathrm{s}$, more than $90 \%$ of flashes occurred downshear in both the storm core and the outer band region (defined as the region located at 100-300 km from the storm center).

[6] Cecil et al. [2002] used data from the Tropical Rainfall Measuring Mission (TRMM) satellite to investigate 45 hurricanes. They combined radar reflectivity parameters and lightning (cloud-to-ground and in cloud) data from the TRMM Lightning Imaging Sensor (LIS). Using greater ice scattering (lower 85 and $37 \mathrm{GHz}$ brightness temperatures) and increased lightning frequency to indicate more intense convection, this study showed that hurricanes are dominated by stratiform rain and relatively weak convection.

[7] There have been a number of more recent studies of lightning activity within intense tropical cyclones, which are generally in agreement with the previous studies of Lyons and Keen [1994] and Molinari et al. [1994, 1999] discussed above. Shao et al. [2005] reported inner core lightning outbursts correlated with intensity change in hurricanes Katrina and Rita (2005) using ground-based sensors in the High Plains and Florida known as the Los Alamos Sferics Array (LASA). With data from the Vaisala Long-range Lightning Detection Network (LLDN), Demetriades and Holle [2006] and Squires and Businger [2008] reported similar results in North Atlantic (including Katrina and Rita) and Eastern North Pacific hurricanes. Price et al. [2009] observed a statistical increase of lightning about 30 hours prior to intensification using a $10^{\circ}$ by $10^{\circ}$ spatial resolution and 6 hour time resolution of data from the World Wide Lightning Location Network (WWLLN) for 56 hurricanes all over the globe.

[8] As noted above, there have only been a few previous reports of polarities and peak currents of lightning in trop- ical cyclones, and these observations were limited to periods when the storms approached land [Samsury and Orville, 1994; Molinari et al., 1999]. To date, there have been no published reports of charge moment changes, an important metric for lightning strength, in tropical cyclone lightning. Including polarity and energetic properties of lightning might lead to a clearer picture of the connection between inner core lightning and tropical cyclone intensity changes, and moreover, it could provide important information about how tropical cyclones electromagnetically couple to the middle and upper atmosphere.

[9] In this investigation, we use WWLLN (http://wwlln. net/), a real-time network that covers the entire globe, along with lightning-generated extremely low and low-frequency (ELF/VLF; $3 \mathrm{~Hz}$ to $30 \mathrm{kHz}$ ) magnetic fields observed at Duke University, to study the polarity and energetics (peak currents and vertical impulse charge moments changes) of inner core lightning in hurricanes Emily, Katrina, and Rita. WWLLN data has a distinct advantage over satellite lightning data (e.g., OTD and LIS) that only include lightning from a particular storm for a few minutes each day, and it has an advantage over data from extended regional lightning networks (e.g., LLDN) that include a limited global region. Thus, this is the first study of inner core lightning polarities, peak currents, and charge moment changes for the complete lifetime of hurricanes. Our work is a continuation of the analysis by Solorzano et al. [2008] of North Atlantic and Western North Pacific tropical cyclones using WWLLN, and our motivations are twofold: (1) Do the rates, locations, polarities, and energetics of inner core lightning relate to tropical cyclone intensity? (2) Are the peak currents and vertical impulse charge moment changes of inner core lightning in tropical cyclones large enough to drive significant perturbations in the lower ionosphere and/or produce transient luminous events (TLEs) such as elves and sprites?

\section{Data Sets}

[10] WWLLN provides real-time lightning locations globally by measuring the time of group arrival (TOGA) of very low frequency (VLF) radiation $(3-30 \mathrm{kHz})$ emanating from lightning discharges [Dowden et al., 2002; Rodger et al. 2006]. In 2005, when hurricanes Emily, Katrina, and Rita occurred, WWLLN was composed of between 20 and 23 active stations around the world. At least five stations had to detect radiation from a stroke for it to be accurately located. The location accuracy and efficiency of WWLLN have been estimated for certain regions of the globe by comparison to regional, ground-based lightning detection systems [Lay et al., 2004; Rodger et al., 2005, 2006, 2009; Jacobson et al., 2006]. All of these comparisons with other lightning networks showed that most WWLLN located lightning had peak currents greater than about $30 \mathrm{kA}$. Rodger et al. [2009] used a comparison between WWLLN and the New Zealand Lightning Detection Network (NZLDN) and Monte Carlo simulation techniques to estimate the global location accuracy of WWLLN [see Rodger et al., 2009, Figure 5]. For the North Atlantic basin during 2005, the location accuracy ranged from about $8-12 \mathrm{~km}$. Comparisons with OTD and LIS lightning data suggest that the overall WWLLN efficiency was about $5-10 \%$ of cloud-to-ground lightning in this region during 2005, and comparisons with 

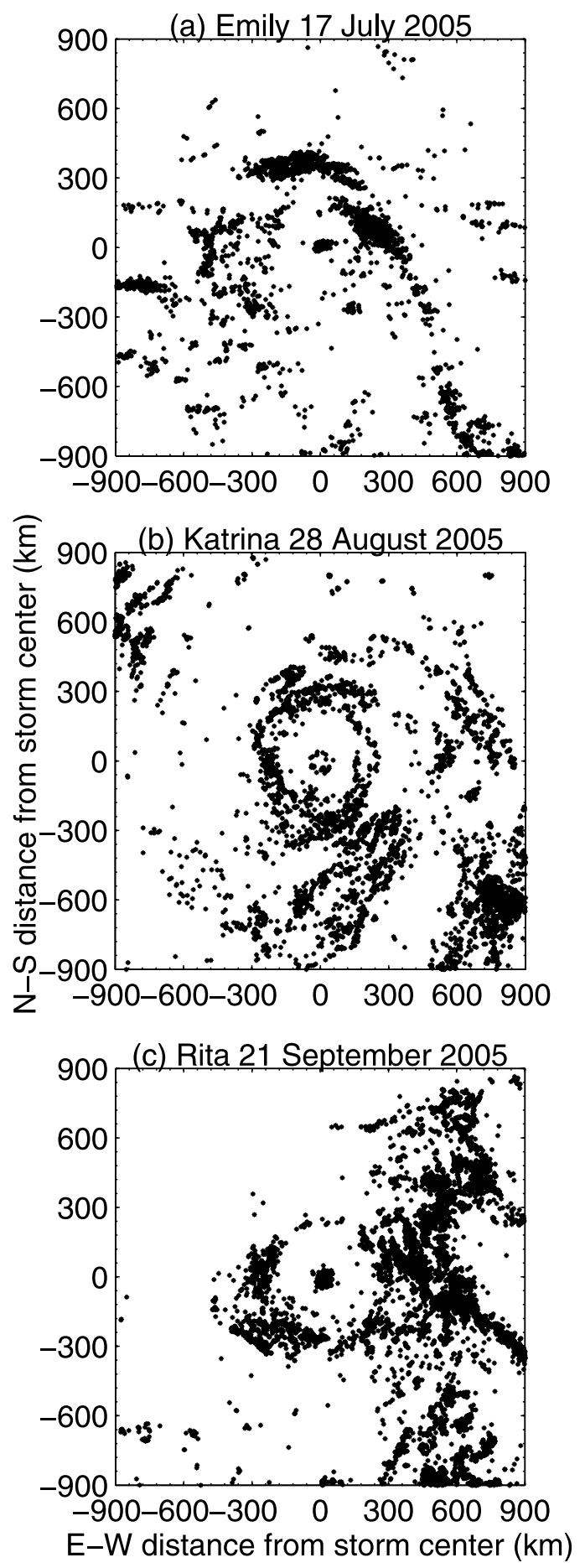

Figure 1. WWLLN lightning data for hurricanes (a) Emily, (b) Katrina, and (c) Rita plotted in storm-centered coordinate systems for 24 hour periods.

NZLDN suggest that the diurnal change in WWLLN cloudto-ground detection efficiency was less than a factor of two (C. J. Rodger, personal communication, 2009). Moreover, a recent study has shown that the WWLLN detection efficiency was about $26 \%$ for parent lightning of optically confirmed TLEs over the United States in 2007 [Lyons et al., 2009].

[11] The Duke sensors used for this work were one pair of magnetic field coils sampled at $100 \mathrm{kHz}$ to measure the vector horizontal magnetic field. From these data we compute the vertical impulse charge moment change and estimate the peak current of individual lightning strokes. During some periods the data were sampled continuously, and in other periods the data were sampled in a triggered mode. The impact of this on the results is noted throughout the paper. The magnetic sensors have a flat passband of $50 \mathrm{~Hz}$ to $25 \mathrm{kHz}$. Absolute timing using GPS was validated to better than $20 \mu$ s using NLDN data. VLF-based measurements of the azimuth to the lightning source have an uncertainty of about $2^{\circ}$. Hurricane wind, pressure, and best track data, along with storm summaries, were obtained from the National Hurricane Center (NHC; http://www. nhc.noaa.gov/pastall.shtml).

\section{Method}

[12] Using the storm track data from the NHC, we found the distance of the WWLLN located lightning events from the location of the minimum central pressure for each storm. Lightning events that occurred within $100 \mathrm{~km}$ of the minimum central pressure were labeled as inner core lightning. The WWLLN located inner core lightning were matched with events measured by the Duke ELF/VLF system that agreed in space (within $5^{\circ}$ azimuth) and time (within $1 \mathrm{~ms}$ ). The lightning polarities were determined from the polarity of the ELF signal component received at Duke. The vertical impulse charge moment changes for these events were determined by processing the magnetic field waveforms according to the method of Cummer and Inan [2000]. Vertical impulse charge moment change $\left(\mathrm{iM}_{\mathrm{q}}\right)$ is defined as the product of the cloud charge removed by vertical currents within $2 \mathrm{~ms}$ of the return stroke and the mean height of this removed charge. Uncertainties in these measurements are estimated to be $\pm 25 \%$ due to noise, calibration uncertainties, and modeling uncertainties. The charge moment changes presented here were measured with the same sensors and the same technique as measurements presented in other recent studies [e.g., Cummer and Lyons, 2005]. The charge moment changes here can thus be directly compared to many of those in the recent literature.

[13] Peak currents were estimated from the maximum amplitude of the received VLF signal components. Through a statistical analysis of many thousands of lightning strokes, we have found that distance-normalized peak VLF fields are proportional to NLDN-reported peak currents, enabling estimates of the peak current from our VLF data with an uncertainty of approximately $\pm 25 \%$. Not all lightning located by WWLLN had clearly identifiable signals measured by the Duke system due to noise from other thunderstorms or local phenomena. For Emily, 630 of 641 WWLLN events could be measured, and for Katrina 432 of 509 events could be measured. During these storms the VLF system sampled the data continuously. For Rita, only 677 of 2359 events could be measured. The lower percentage of matches for Rita is because the Duke system was operating in a triggered rather than continuous mode during this storm. From comparisons with NLDN, we know that events with peak currents above about $30 \mathrm{kA}$ (the vast majority of those located by WWLLN) are very likely to be CG lightning. Positive polarity events with peak currents less than about $15 \mathrm{kA}$ are likely to be in-cloud (IC) lightning [Cummins et al., 1998], and positive 

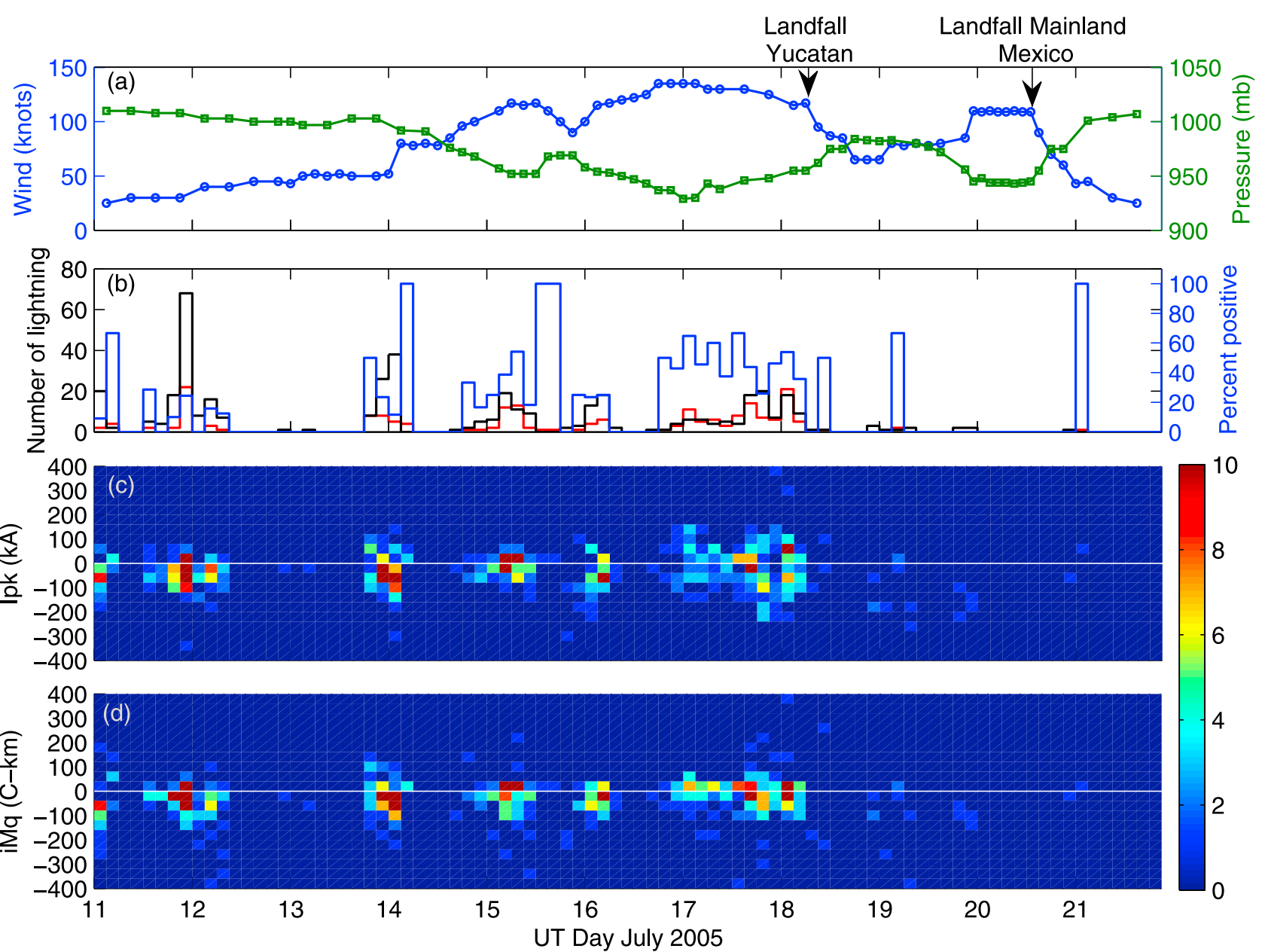

Figure 2. Temporal evolution of inner core lightning in Hurricane Emily. (a) Maximum sustained winds (1 min averages in knots shown as blue circles) and minimum central pressure (green squares). (b) Lightning activity within $100 \mathrm{~km}$ of the best track storm center binned in 3 hour intervals (black bars are negative CG lightning, red bars are CG positive lightning, and blue bars are percent positive lightning). (c) A spectrogram of peak currents $\left(\mathrm{I}_{\mathrm{pk}}\right)$ using 3 hour by $40 \mathrm{kA}$ bins. (d) A spectrogram of vertical impulse charge moment changes $\left(\mathrm{iM}_{\mathrm{q}}\right)$ using 3 hour by $40 \mathrm{C} \mathrm{km}$ bins. The color bar indicates the number of lightning events in each bin, and dark red represents 10 or more events. Events with $\mathrm{I}_{\mathrm{pk}}$ and $\mathrm{iM}_{\mathrm{q}}$ magnitudes greater than $400 \mathrm{kA}(\mathrm{C} \mathrm{km})$ are included in the $360-400 \mathrm{kA}(\mathrm{C} \mathrm{km})$ bins.

events with peak currents of 15-30 kA could be either CG or IC lightning.

\section{Observations}

[14] Hurricanes Emily, Katrina, Rita were Category 5 storms on the Saffir-Simpson Hurricane Scale (SSHS; see http:// www.nhc.noaa.gov/aboutsshs.shtml) that occurred during 2005 in the North Atlantic basin. Figure 1 shows WWLLN lightning data for the three hurricanes plotted in stormcentered coordinate systems for 24 hour periods. This was accomplished by finding the distance of the lightning events from the best track location of the minimum central pressure. Figure 1a shows lightning for Emily during UT day 17 July when it was a Category 5 storm in the Caribbean Sea. Figure $1 \mathrm{~b}$ shows lightning for Katrina during UT day 28 August when it intensified from a Category 3 to 5 storm in the Gulf of Mexico. Figure 1c shows lightning for Rita during UT day 21 September when it intensified from a Category 2 to 5 storm in the Gulf of Mexico. In all cases, the WWLLN lightning data generally show the radial pattern previously observed by Molinari et al. [1999] during other North Atlantic basin hurricanes. There are three distinct regions: a weak density maximum for the eyewall (region within about $40 \mathrm{~km}$ of the center), a distinct area of minimum activity at approximately $80-200 \mathrm{~km}$ from the eyewall, and the main, broader maximum on the rainband region, outside the $200 \mathrm{~km}$ radius.

[15] Solorzano et al. [2008] studied the temporal and spatial evolution of lightning in hurricanes Katrina and Rita and showed the WWLLN results agreed well with results from LASA [Shao et al., 2005] and LLDN [Demetriades and Holle, 2006; Squires and Businger, 2008]. Here we examine the polarities, peak currents, and vertical impulse vertical charge moments changes of inner core lightning (within $100 \mathrm{~km}$ of the minimum pressure) in Emily, Katrina, 

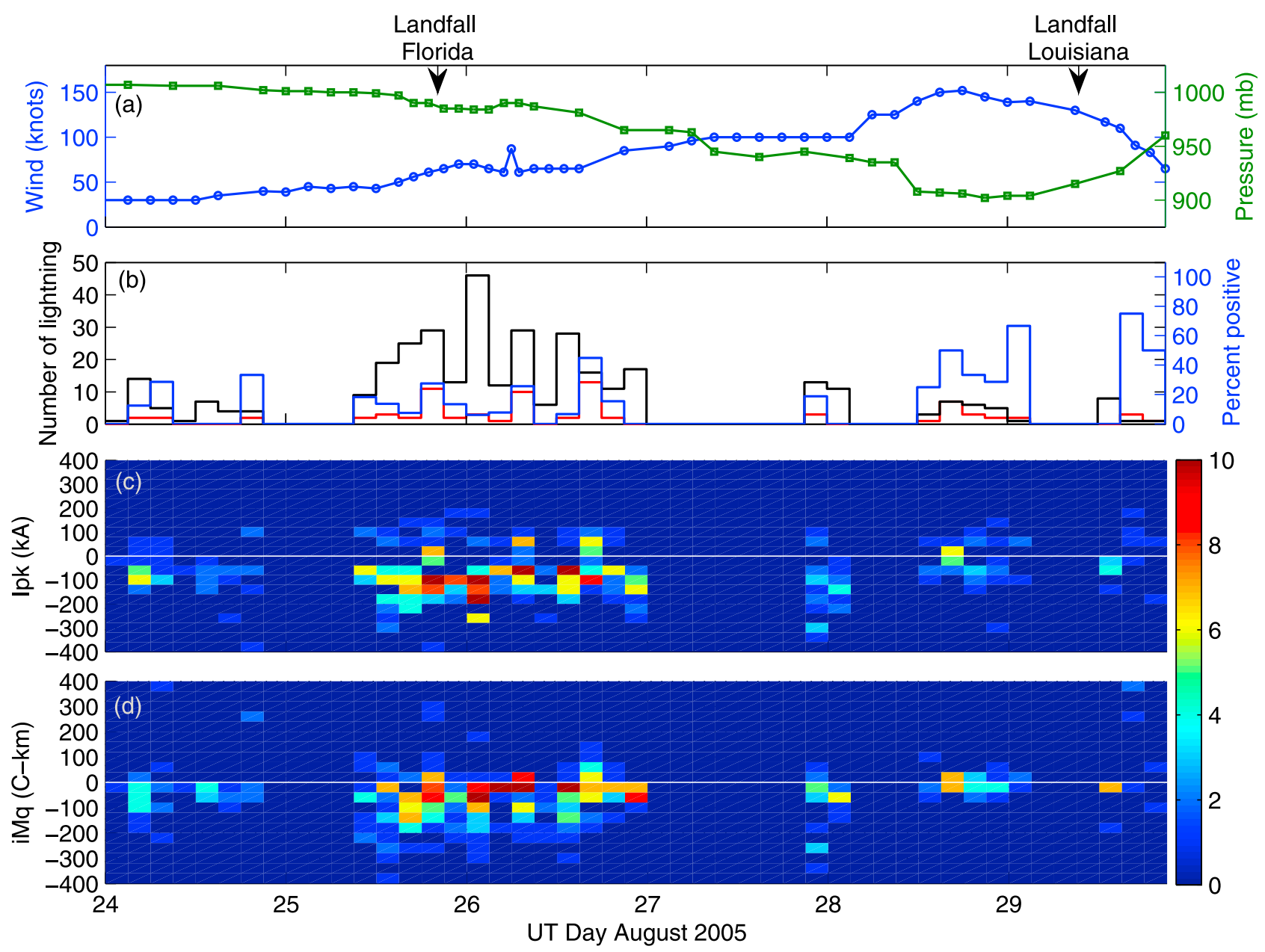

Figure 3. Temporal evolution of inner core lightning in Hurricane Katrina (see Figure 2 for details).

and Rita. Inner core lightning events can be seen in Figure 1 (events within $100 \mathrm{~km}$ of the origin of Figures $1 \mathrm{a}, 1 \mathrm{~b}$, and 1c). We are currently investigating rainband lightning (beyond $100 \mathrm{~km}$ from the minimum pressure) in these storms and plan to present these results in future publications.

[16] Figures 2, 3, and 4 show the temporal evolutions of polarities (Figures 2b, 3b, and 4b), peak currents (Figures 2c, $3 c$, and $4 c$ ), and vertical impulse charge moment changes (Figures 2d, 3d, and 4d) in Emily, Katrina, and Rita. Figures 2, 3 , and 4 also show the maximum sustained winds (1 min averages in knots) and minimum central pressure data to indicate storm intensity (Figures 2a, 3a, and 4a). As shown by Solorzano et al. [2008] and studies using other networks [Shao et al. 2005; Demetriades and Holle, 2006; Squires and Businger, 2008], inner core lightning outbreaks tended to occur prior to and during intensity change in these storms. The new observation in Figures $2 \mathrm{~b}, 3 \mathrm{~b}$, and $4 \mathrm{~b}$ is the polarity of these inner core lightning (black bars are negative $\mathrm{CG}$ lightning, red bars are positive CG lightning, and blue bars are the percent of positive lightning). Most of these lightning were negative in polarity for most outbreaks. Notable exceptions were usually just prior to or during periods of storm weakening. For instance, during Emily (Figure 2 and Table 1) 44\% of lightning were positive during the outbreak on 15 July when it weakened from a Category 4 to 2 storm in the Caribbean Sea. During 16-18 July, 47\% of the lightning were positive as it weakened from a Category 5 to 1 storm prior to and during landfall on Yucatan Peninsula.

[17] Similar temporal patterns are observed for Katrina and Rita. During Katrina (Figure 3 and Table 2) positive lightning became more prevalent (29\% to $41 \%$ ) during 28 29 August when it weakened from a Category 5 to 3 storm prior to landfall in Louisiana. For Rita (Figure 4 and Table 3) there was a higher percentage of positive CG lightning after landfall on 24 September when it weakened from a Category 3 to 1 storm. Importantly, we must be cautious in comparing Rita with Emily and Katrina, since the Duke system was operating in triggered mode during Rita and only recorded waveforms for about $30 \%$ of the WWLLN located inner core lightning. Note that this $30 \%$ is likely the fraction with the highest peak currents, resulting in peak VLF fields that exceeded the system trigger threshold.

[18] Figures 2c, 3c, and 4c show the temporal evolution of inner core lightning peak currents $\left(\mathrm{I}_{\mathrm{pk}}\right)$. WWLLN is most sensitive to $\mathrm{I}_{\mathrm{pk}}$ amplitudes greater than about $30 \mathrm{kA}$, and based on our detection efficiency estimated for this region, our results represent the top $5-10 \%$ of the largest peak current inner core CG lightning. That said, the majority of peak currents were above $50 \mathrm{kA}$ and many were above $100 \mathrm{kA}$, which is further shown by the histogram of peak currents for 

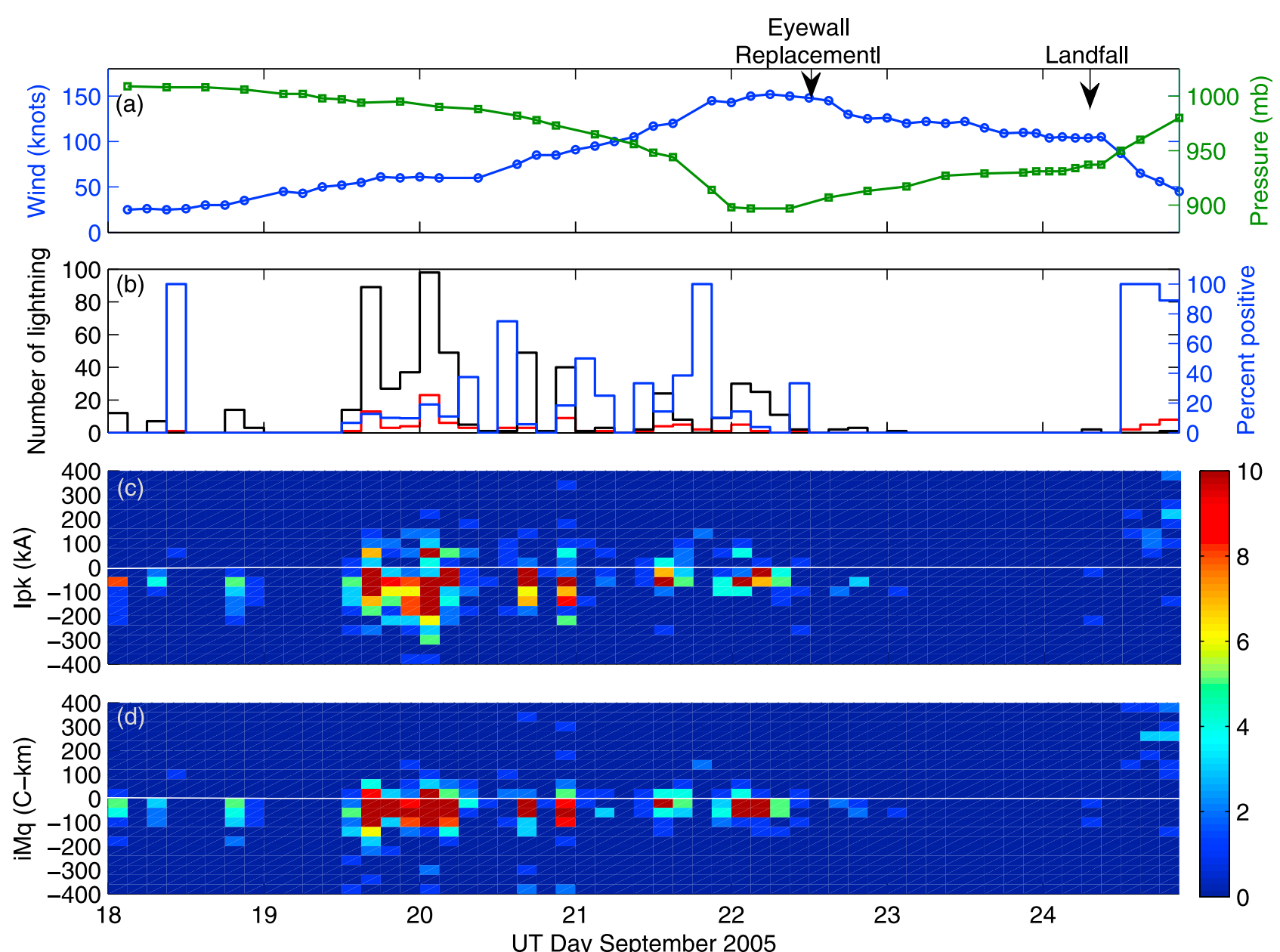

Figure 4. Temporal evolution of inner core lightning in Hurricane Rita (see Figure 2 for details).

the entire duration of all three storms in Figure 5. Figures 2c, $3 \mathrm{c}$, and $4 \mathrm{c}$ show no clear relationship between $\mathrm{I}_{\mathrm{pk}}$ magnitude and storm intensity for these hurricanes. Figures $2 d, 3 d$, and $4 \mathrm{~d}$ show the temporal evolution of inner core lightning vertical impulse charge moment changes $\left(\mathrm{iM}_{\mathrm{q}}\right)$. Just as for the peak currents values, there is no clear relationship between $\mathrm{iM}_{\mathrm{q}}$ amplitudes and storm intensity for these hurricanes. The majority of $\mathrm{iM}_{\mathrm{q}}$ amplitudes were less than $50 \mathrm{C} \mathrm{km}$ in magnitude, which is further shown in Figure 5.
[19] Figure 6 shows the spatial distribution of polarities, peak currents, and vertical impulse charge moment changes for inner core lightning in storm-centered coordinates integrated for the complete lifetimes of Emily, Katrina, and Rita. No clear relationships between polarity, $\mathrm{I}_{\mathrm{pk}}$, or $\mathrm{iM}_{\mathrm{q}}$ and location relative to the storm center are apparent for these hurricanes. For Emily and Katrina, most inner core lightning were within about $40 \mathrm{~km}$ of the storm center and were likely located in the primary eyewall cloud. The lightning outside of about $40 \mathrm{~km}$ in the inner core were located in the inner

Table 1. Percent of Positive Cloud-to-Ground Lightning for Inner Core Lightning Outbreaks in Hurricane Emily ${ }^{\mathrm{a}}$

\begin{tabular}{lccc}
\hline \multicolumn{1}{c}{ Time Period (UT) } & Intensity Change & Number of Lightning & Percent Positive \\
\hline 11 Jul 0000-0600 & Strengthen & 28 & 21 \\
11 Jul 1200 to 12 Jul 0900 & Strengthen & 148 & 20 \\
12 Jul 2100 to 13 Jul 0600 & Strengthen & 97 & 0 \\
13 Jul 1800 to 14 Jul 0600 & Strengthen & 49 & 26 \\
14 Jul 1500 to 15 Jul 0600 & Strengthen & $\mathbf{3 9}$ & 33 \\
15 Jul 0600-2100 & Weaken & 47 & $\mathbf{4 4}$ \\
15 Jul 2100 to 16 Jul 0900 & Strengthen & $\mathbf{1 9 5}$ & $\mathbf{4}$ \\
16 Jul 1800 to 18 Jul 1200 & Weaken & 4 & $\mathbf{4 7}$ \\
18 Jul 2100 to 19 Jul 0900 & Strengthen & $\mathbf{2}$ & 0 \\
19 Jul 1800 to 20 Jul 0000 & Strengthen & 630 & $\mathbf{5 0}$ \\
20 Jul 2100 to 21 Jul 0300 & Weaken & 32 \\
11 Jul 0000 to 22 Jul 0000 (Entire Storm) & Not Applicable & & \\
\hline
\end{tabular}

${ }^{\mathrm{a}}$ Bold represents data during periods of storm weakening. 
Table 2. Percent of Positive Cloud-to-Ground Lightning for Inner Core Lightning Outbreaks in Hurricane Katrina ${ }^{\mathrm{a}}$

\begin{tabular}{lccc}
\hline Time Period (UT) & Intensity Change & Number of Lightning & Percent Positive \\
\hline 24 Aug 0000-2100 & Strengthen & 42 & 115 \\
25 Aug 0900 to 26 Aug 0000 & Strengthen & $\mathbf{6 2}$ & 14 \\
26 Aug 0000-0600 & Weaken & 134 & $\mathbf{6}$ \\
26 Aug 0600 to 27 Aug 0000 & Strengthen & 27 & 20 \\
27 Aug 2100 to 28 Aug 0300 & Strengthen & $\mathbf{2 7}$ & 11 \\
28 Aug 1200-2100 & Strengthen/ Weaken & $\mathbf{1 0}$ & $\mathbf{4 1}$ \\
$\mathbf{2 8}$ Aug 2100 to 29 Aug 0300 & Weaken & $\mathbf{4}$ & $\mathbf{4 0}$ \\
$\mathbf{2 9}$ Aug 1200-2100 & Weaken & 432 & 18 \\
24 Aug 0000 to 30 Aug 0000 (Entire Storm) & Not Applicable & $\mathbf{2 9}$ \\
\hline
\end{tabular}

${ }^{\mathrm{a}}$ Bold represents data during periods of storm weakening.

rainbands and stratiform regions (see Willoughby [1988] for a discussion of inner core structure). In Rita, lightning were less concentrated near the best track storm center. There appears to be a dense area of lightning in the southwest quadrant, which might indicate that best track storm location was in error when these lightning occurred.

\section{Discussion}

[20] We observe an increase in the relative amount of positive cloud-to-ground lightning just prior to and during most periods of storm weakening in the three hurricanes investigated. Based on previous comparisons of the Duke magnetic field measurements and NLDN data, the high peak fields of these events suggest that the vast majority $(>90 \%)$ of them were indeed positive CG lightning. However, since WWLLN only locates the highest peak current cloud-toground lightning (greater than $30 \mathrm{kA}$ ) in these storms, we must be cautious in interpreting these results. Indeed, additional polarity studies should be conducted on a larger number of storms using other lightning networks and WWLLN to confirm our findings. Nonetheless, an increase in positive lightning before and during storm weakening was clearly observed in all three hurricanes we examined, which suggests that real-time polarity observations could prove useful for intensity forecasting.

[21] We do not identify particular locations within the inner core that were preferred by positive lightning (Figure 6). The positive discharges were dispersed throughout the inner core region, not just located outside of the eyewall. Thus, we cannot say that positive lightning were located in stratiform regions, as previously reported by Molinari et al. [1999]. In future works, we intend to combine our polarity results with radar data (ground, satellite, and airborne based) in order to investigate the convective structures associated with positive lightning, which might provide insight on the connection between positive discharges and weakening stages.

[22] The peak current and vertical impulse charge moment change observations have implications for the production of transient luminous events (TLEs; e.g., elves and sprites) and lightning-driven perturbations in the lower ionosphere. Modeling and remote observations suggest that elves are the result of electromagnetic pulses (EMPs) generated by large peak current lightning return strokes (both negative and positive polarity) exciting and ionizing the lower ionosphere at 90-100 km [Taranenko et al., 1993a; Fernsler and Rowland, 1996; Inan et al., 1997; Barrington-Leigh and Inan, 1999]. Barrington-Leigh and Inan studied 86 events detected by NLDN with peak currents greater than $38 \mathrm{kA}$ and observed correlated elves for $52 \%$ of these using a photometric array, and for peak currents above $57 \mathrm{kA}$, all 34 NLDN flashes had correlated elves. A more recent study [Cheng et al., 2007] generally agreed with these results, setting the threshold for EMP induced conductivity perturbations in the ionosphere at about 40-60 kA. Thus, it may be likely that a significant fraction of all WWLLN-detected cloud-to-ground lightning are producing elves, since the network is most sensitive to peak currents greater than about $30 \mathrm{kA}$. Although, to date, there have been very few reports of electrical perturbations and TLEs above tropical storms. Two notable exceptions include satellite measurements of a transient electric field disturbance above Hurricane Debbie (1992) [Burke et al., 1992] and video imaging of a gigantic jet above Tropical Storm Cristobal (2008) [Cummer et al., 2009].

Table 3. Percent of Positive Cloud-to-Ground Lightning for Inner Core Lightning Outbreaks in Hurricane Rita ${ }^{\mathrm{a}}$

\begin{tabular}{lccc}
\hline \multicolumn{1}{c}{ Time Period (UT) } & Intensity Change & Number of Lightning & Percent Positive \\
\hline 18 Sep 0600-1200 & Strengthen & 18 & 17 \\
18 Sep 1800 to 19 Sep 0000 & Strengthen & 372 & 0 \\
19 Sep 1200 to 20 Sep 0900 & Strengthen & 56 & 14 \\
20 Sep 1200-1800 & Strengthen & 55 & 11 \\
20 Sep 2100 to 21 Sep 0600 & Strengthen & 91 & 20 \\
21 Sep 0900 to 22 Sep 0300 & Strengthen & $\mathbf{4 0}$ & $\mathbf{5}$ \\
22 Sep 0300-1200 & Weaken & $\mathbf{5}$ & $\mathbf{5}$ \\
22 Sep 1500-2100 & Weaken & $\mathbf{1 6}$ & $\mathbf{0}$ \\
24 Sep 1200-2100 & Weaken & 677 & $\mathbf{9 4}$ \\
18 Sep 0000 to 25 Sep 0000 (Entire Storm) & Not Applicable & & 16 \\
\hline
\end{tabular}

${ }^{\mathrm{a} B o l d}$ represents data during periods of storm weakening. 

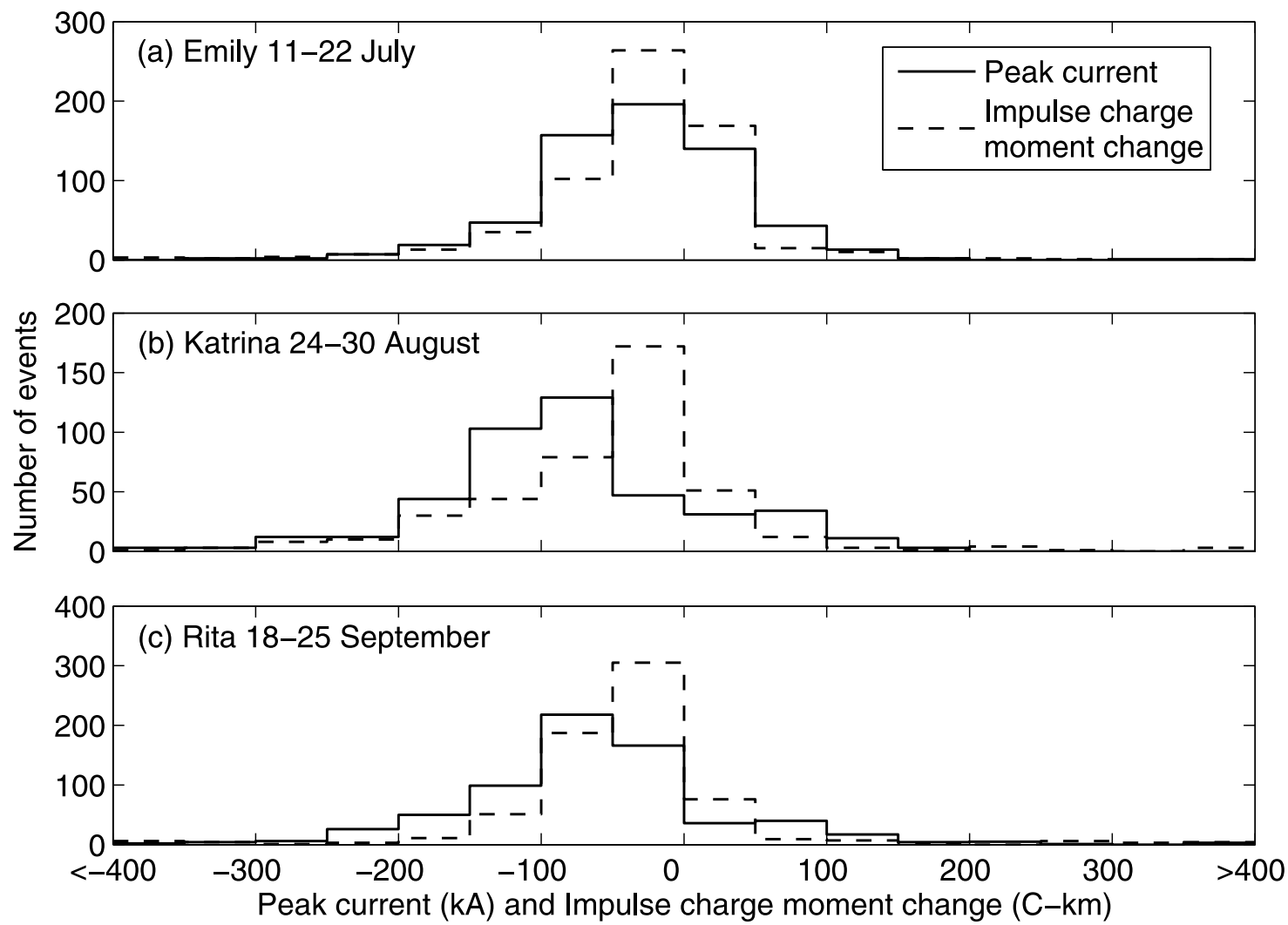

Figure 5. Histogram of peak current and vertical impulse charge moment changes for inner core lightning in hurricanes (a) Emily, (b) Katrina, and (c) Rita. Events with $\mathrm{I}_{\mathrm{pk}}$ and $\mathrm{iM}_{\mathrm{q}}$ magnitudes greater than $400 \mathrm{kA}(\mathrm{C} \mathrm{km})$ are included in the $350-400 \mathrm{kA}(\mathrm{C} \mathrm{km})$ bins.

[23] Table 4 lists the number of inner core lightning events in Emily, Katrina, and Rita that surpassed $40 \mathrm{kA}$ in magnitude, the approximate threshold for elve production according to the works of Barrington-Leigh and Inan [1999] and Cheng et al. [2007]. Hundreds of inner core lightning for each hurricane were above this threshold for elve production. Importantly, as shown in Figures 2, 3, and 4 , these high peak current lightning tended to occur in short-duration episodes, with tens to hundreds of high peak current lightning occurring in a few hours. Recent modeling work by E. H. Lay et al. (Temporal-spatial modeling of nonlinear electron density enhancement due to successive lightning strokes, submitted to Journal of Geophysical Research, 2009), which is based on earlier studies by Taranenko et al. [1993b] and Rodger et al. [2001], has shown that lightning strokes can have an accumulated effect on the lower ionosphere. According to Lay et al. (submitted manuscript, 2009), multiple high peak current lightning strokes that occur near in space and time, like the inner core lightning studied here, drive EMPs that have an additive nonlinear effect on the electron density of the lower ionosphere. Hence, our results suggest that the inner core regions of intense hurricanes might drive strong electron density perturbations in the lower ionosphere during these lightning outbreaks.

[24] We should point out that tropical cyclones are not the most active lightning producers globally. Even the most electrically active tropical cyclone is a weak lightning producer compared to a continental mesoscale convective system, where lightning cloud-to-ground flash rates can exceed 10,000 per hour [see, e.g., Zipser et al., 2006]. Most tropical cyclones are probably more similar to a typical mesoscale convective system in terms of lightning activity, even when considering higher peak current events.

[25] Sprites are driven by large charge moment change lightning, which are predominantly positive in polarity [Boccippio et al., 1995]. These lightning generate a large quasi-static electric field above the thundercloud, which leads to breakdown seen as sprites [Pasko et al., 1997]. Table 4 lists the number of inner core lightning events in Emily, Katrina, and Rita that surpassed $350 \mathrm{C} \mathrm{km}$ in magnitude, the approximate threshold for prompt, or shortdelayed, sprite initiation based on an investigation of sprites over the U.S. High Plains by Cummer and Lyons [2005]. Only a few events surpassed this vertical impulse charge moment change threshold. However, many sprites are dominantly produced by continuing current charge moment change [Li et al., 2008] in lightning with only modest impulse charge moment changes. Determining whether the inner core regions of intense hurricanes are or are not active sprite producers will require detailed analysis of the charge moment change on times scales longer than $2 \mathrm{~ms}$.

[26] There has been very little systematic investigation of TLEs above tropical cyclones. We examined the TLE 
(a) Emily Polarity

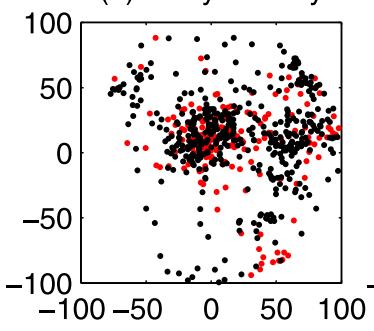

(b) Emily Ipk

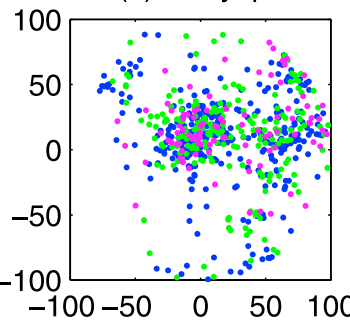

(c) Emily iMq

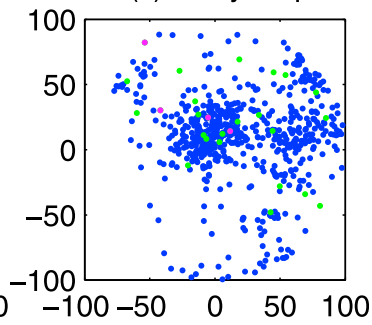

(d) Katrina Polarity

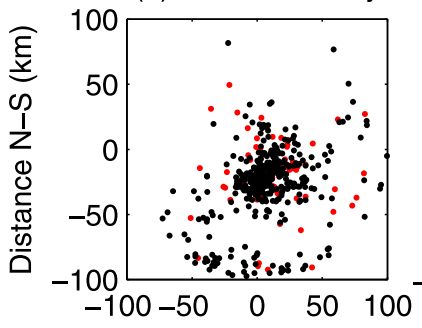

(e) Katrina Ipk

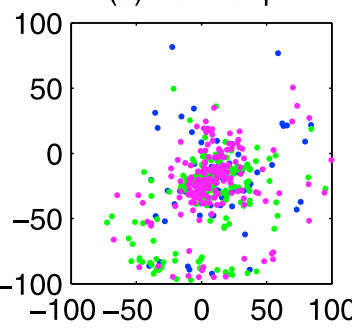

(f) Katrina iMq

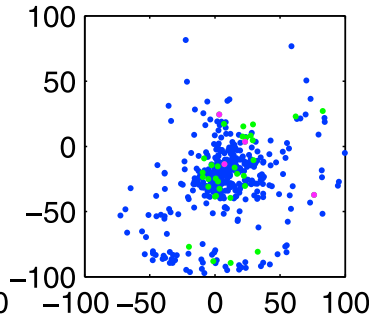

(h) Rita Ipk
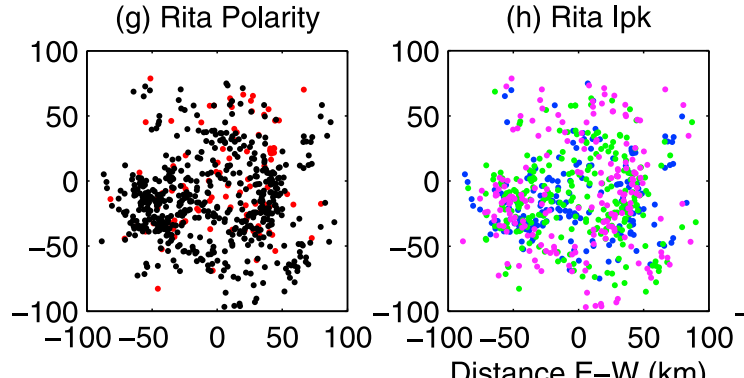

(i) Rita iMq



Figure 6. Spatial distribution of inner core lightning in hurricanes (a, b, and c) Emily, (d, e, and f) Katrina, and $(\mathrm{g}, \mathrm{h}$, and i) Rita in storm-centered coordinates for the entire duration of each storm. Figures $6 \mathrm{a}, 6 \mathrm{~d}$, and $6 \mathrm{~g}$ show polarity (negative CG lightning are black and positive CG lightning are red). Figures $6 \mathrm{~b}$, $6 \mathrm{e}$, and $6 \mathrm{~h}$ show peak current $\left(\mathrm{I}_{\mathrm{pk}}\right)$ magnitudes $(0-50 \mathrm{kA}$ are blue, 50-100 kA are green, and greater than $100 \mathrm{kA}$ are magenta). Figures $6 \mathrm{c}, 6 \mathrm{f}$, and $6 \mathrm{i}$ show vertical impulse charge moment change $\left(\mathrm{iM}_{\mathrm{q}}\right)$ magnitudes $(0-175 \mathrm{C} \mathrm{km}$ are blue, $175-350 \mathrm{C} \mathrm{km}$ are green, and greater than $350 \mathrm{C} \mathrm{km}$ are magenta).

database from the ISUAL instrument aboard the FORMOSAT satellite, and we found no TLEs above hurricanes Emily, Katrina, and Rita. We have also initiated a search for ISUAL observed TLEs in all tropical cyclones globally since 2004. These results will be presented in future publications.

\section{Conclusions and Future Work}

[27] We find episodic inner core lightning outbreaks prior to and during most changes in storm intensity (winds and central pressure) in hurricanes Emily, Katrina, and Rita, which is in strong agreement with past investigations [Molinari et al., 1994, 1999; Squires and Businger, 2008; Solorzano et al., 2008]. As a novel result, we find that the relative number of positive CG lightning increased in the inner core prior to and during periods of storm weakening. This change in the temporal distribution of positive CG lightning might prove useful for forecasting hurricane intensity change. However, since WWLLN only locates the highest peak current lightning in these storms, further studies are needed to support this result. No relationship between the location of negative and positive CG lightning and storm intensity is found, and we find no apparent correspondence between spatial and temporal distributions of energetic magnitudes $\left(\mathrm{I}_{\mathrm{pk}}\right.$ and $\left.\mathrm{iM}_{\mathrm{q}}\right)$ and storm intensity.

[28] Another new finding is that the majority of inner core lightning located by WWLLN had peak currents that surpassed the threshold needed to produce elves and drive

Table 4. Number of Inner Core Lightning Peak Currents Above Elve Thresholds and Impulse Vertical Charge Moment Changes Above Short-Delayed Sprite Thresholds ${ }^{\mathrm{a}}$

\begin{tabular}{lccccc}
\hline & \multicolumn{2}{c}{$\left|\mathrm{I}_{\mathrm{pk}}\right|>40 \mathrm{kA}$} & & \multicolumn{2}{c}{$\left|\mathrm{iM}_{\mathrm{q}}\right|>350 \mathrm{C} \mathrm{km}$} \\
\cline { 2 - 3 } \cline { 6 - 6 } Hurricane & Negative & Positive & & Negative & Positive \\
\hline Emily & 275 & 88 & & 3 & 1 \\
Katrina & 328 & 57 & & 1 & 3 \\
Rita & 467 & 83 & & 6 & 4 \\
\hline
\end{tabular}

${ }^{\mathrm{a}} \mathrm{Here} \mathrm{I}_{\mathrm{pk}}$ is inner core lightning peak currents and $\mathrm{iM}_{\mathrm{q}}$ is vertical impulse charge moment changes. 
electron density perturbations in the lower ionosphere $(80$ $105 \mathrm{~km}$ ), but very few of these lightning had vertical impulse charge moment changes that were large enough to initiate short-delayed sprites. Since these high peak current lightning occurred in short-duration outbreaks in a localized region in the inner core, there could have been an additive effect on the lower ionosphere due to EMPs from these multiple lightning events. Our results suggest that these hurricanes might be significant drivers of electron density perturbations in the lower ionosphere during these inner core lightning outbreaks.

[29] In the near future, we intend to combine our polarity results with radar data in order to investigate the convective structures associated with positive lightning, which might explain why positive discharges are predominant during weakening stages. Work is currently underway to study polarity and energetics of lightning in rainband regions outside the inner core. To test the role of tropical cyclone inner core lightning as drivers of electron density perturbations in the lower ionosphere, we propose that future observational campaigns (e.g., optical and radar studies) of the middle and upper atmosphere be conducted in the vicinity of tropical cyclones.

[30] Acknowledgments. We are grateful to Craig Rodger and Erin Lay for assisting us with WWLLN data processing. We thank the many WWLLN hosts throughout the globe for housing and maintaining the VLF receivers. This work was partially supported by the Digipen Institute of Technology, Bard High School Early College Queens, and a grant from Mindlin Foundation to the University of Washington. J.N.T. was partially supported by a USGS Mendenhall Fellowship. This research was partially supported by NSF Dynamic and Physical Meteorology Program grant ATM-0642757 to Duke University.

[31] Zuyin Pu thanks the reviewer for their assistance in evaluating this manuscript.

\section{References}

Barrington-Leigh, C. P., and U. S. Inan (1999), Elves triggered by positive and negative lightning discharges, Geophys. Res. Lett., 26, 683-686, doi:10.1029/1999GL900059.

Boccippio, D., E. Williams, S. Heckman, W. Lyons, I. Baker, and R. Boldi (1995), Sprites, ELF transients, and positive ground strokes, Science, 269, 1088-1091, doi:10.1126/science.269.5227.1088

Burke, W. J., T. L. Aggson, N. C. Maynard, W. R. Hoegy, R. A. Hoffman, R. M. Candy, C. Liebrecht, and E. Rodgers (1992), Effects of a lightning discharge detected by the DE 2 satellite over Hurricane Debbie, J. Geophys. Res., 97, 6359-6367, doi:10.1029/92JA00305.

Cecil, D. J., and E. J. Zipser (1999), Relationships between tropical cyclone intensity and satellite-based indicators of inner core convection: $85-\mathrm{GHz}$ ice-scattering signature and lightning, Mon. Weather Rev., 127, 103-123, doi:10.1175/1520-0493(1999)127<0103:RBTCIA >2.0.CO;2.

Cecil, D. J., E. J. Zipser, and S. W. Nesbitt (2002), Reflectivity, ice scattering, and lightning characteristics of hurricane eyewalls and rainbands Part I: Quantitative description, Mon. Weather Rev., 130, 769-784, doi:10.1175/1520-0493(2002)130<0769:RISALC >2.0.CO;2.

Cheng, Z., S. A. Cummer, H. T. Su, and R. R. Hsu (2007), Broadband VLF measurement of D region ionospheric perturbations caused by lightning electromagnetic pulses, J. Geophys. Res., 112, A06318, doi:10.1029/ 2006JA011840.

Corbosiero, K. L., and J. Molinari (2002), The effects of vertical wind shear on the distribution of convection in tropical cyclones, Mon. Weather Rev., 130, 2110-2123, doi:10.1175/1520-0493(2002)130<2110: TEOVWS $>2.0 . \mathrm{CO} ; 2$

Cummer, S. A., and U. S. Inan (2000), Modeling ELF radio atmospheric propagation and extracting lightning currents from ELF observations, Radio Sci., 35(2), 385-394, doi:10.1029/1999RS002184.

Cummer, S. A., and W. A. Lyons (2005), Implications of lightning charge moment changes for sprite initiation, J. Geophys. Res., 110, A04304, doi:10.1029/2004JA010812.
Cummer, S. A., J. Li, F. Han, G. Lu, N. Jaugey, W. A. Lyons and T. E. Nelson (2009), Quantification of the troposphere-to-ionosphere charge transfer in a gigantic jet, Nat. Geosci., 2, 617-620, doi:101028/NGEO 607.

Cummins, K. L., M. J. Murphy, E. A. Bardo, W. L. Hiscox, R. B. Pyle, and E. E. Pifer (1998), A combined TOA/MDF technology upgrade of the U.S. National Lightning Detection Network, J. Geophys. Res., 103(D8), 9035-9044, doi:10.1029/98JD00153.

Demetriades, N. W. S., and R. L. Holle (2006), Long range lightning nowcasting applications for tropical cyclones, paper presented at Second Conference on Meteorological Application of Lightning Data, Am. Meteorol. Soc., Atlanta.

Dowden, R. L., J. B. Brundell, and C. J. Rodger (2002), VLF lightning location by time of group arrival (TOGA) at multiple sites, J. Atmos. Sol. Terr. Phys., 64(7), 817-830, doi:10.1016/S1364-6826(02)00085-8.

Fernsler, R. F., and H. L. Rowland (1996), Models of lightning-produced sprites and elves, J. Geophys. Res., 101, 29,653-29,662, doi:10.1029/ 96JD02159.

Inan, U., C. Barrington-Leigh, S. Hansen, V. Glukhov, T. Bell, and R. Rairden (1997), Rapid lateral expansion of optical luminosity in lightning-induced ionospheric flashes referred to as 'elves', Geophys. Res. Lett., 24(5), 583-586, doi:10.1029/97GL00404.

Jacobson, A. R., R. H. Holzworth, J. Harlin, R. L. Dowden, and E. H. Lay (2006), Performance assessment of the World Wide Lightning Location Network (WWLLN), using the Los Alamos Sferic Array (LASA) array as ground-truth, J. Atmos. Oceanic Technol., 23, 1082-1092, doi:10.1175/ JTECH1902.1.

Lay, E. H., R. H. Holzworth, C. J. Rodger, J. N. Thomas, O. Pinto Jr., and R. L. Dowden (2004), WWLL global lightning detection system: Regional validation study in Brazil, Geophys. Res. Lett., 31, L03102, doi:10.1029/2003GL018882.

Li, J., S. A. Cummer, W. A. Lyons, and T. E. Nelson (2008), Coordinated analysis of delayed sprites with high-speed images and remote electromagnetic fields, J. Geophys. Res., 113, D20206, doi:10.1029/ 2008JD010008.

Lyons, W. A., and C. S. Keen (1994), Observations of lightning in convective supercells within tropical storms and hurricanes, Mon. Weather Rev., 122, 1897-1916, doi:10.1175/1520-0493(1994)122<1897:OOLICS >2.0.CO;2.

Lyons, W. A., M. A. Stanley, J. D. Meyer, T. E. Nelson, S. A. Rutledge, T. L. Lang, and S. A. Cummer (2009), The meteorological and electrical structure of TLE-producing convective storms, in Lightning: Principles, Instruments and Applications, edited by H. D. Betz et al., pp. 389-417, doi:10.1007/978-1-4020-9079-017, Springer, New York.

Molinari, J., P. K. Moore, V. P. Idone, R. W. Henderson, and A. B. Saljoughy (1994), Cloud-to-ground lightning in Hurricane Andrew, J. Geophys. Res., 99(D8), 16,665-16,676, doi:10.1029/94JD00722.

Molinari, J., P. K. Moore, and V. P. Idone (1999), Convective structure of hurricanes as revealed by lightning locations, Mon. Weather Rev., 127(4), 520-534, doi:10.1175/1520-0493(1999)127<0520:CSOHAR $>2.0 . C O ; 2$.

Pasko, V. P., U. S. Inan, T. F. Bell, and Y. N. Taranenko (1997), Sprites produced by quasi-electrostratic heating and ionization in the lower ionosphere, J. Geophys. Res., 102, 4529-4562, doi:10.1029/96JA03528.

Price, C., M. Asfur, and Y. Yair (2009), Maximum hurricane intensity preceded by increase in lightning frequency, Nat. Geosci., 2, 329-332, doi:10.1038/NGEO477.

Rodger, C., M. Cho, M. Clilverd, and M. Rycroft (2001), Lower ionospheric modification by lightning-EMP: Simulation of the night ionosphere over the United States, Geophys. Res. Lett., 28(2), 199-202, doi:10.1029/2000GL011951.

Rodger, C. J., J. B. Brundell, and R. L. Dowden (2005), Location accuracy of VLF World Wide Lightning Location (WWLL) network: Post-algorithm upgrade, Ann. Geophys., 23, 277-290.

Rodger, C. J., S. Werner, J. B. Brundell, E. H. Lay, N. R. Thomson, R. H. Holzworth, and R. L. Dowden (2006), Detection efficiency of the VLF World-Wide Lightning Location Network (WWLLN): Initial case study, Ann. Geophys., 24, 3197-3214.

Rodger, C. J., J. B. Brundell, R. H. Holzworth, and E. H. Lay (2009), Growing detection efficiency of the World Wide Lightning Location Network, in Coupling of Thunderstorms and Lightning Discharges to Near-Earth Space: Proceedings of the Workshop, edited by N. B. Crosby, T.-Y. Huang, and M. J. Rycroft, pp. 15-20, doi:10.1063/ 1.3137706, Am. Inst. of Phys., Melville, N. Y.

Samsury, C. E., and R. E. Orville (1994), Cloud-to-ground lightning in tropical cyclones: A study of hurricanes Hugo (1989) and Jerry (1989), Mon. Weather Rev., 122, 1887-1896, doi:10.1175/1520-0493(1994) 122<1887:CTGLIT>2.0.CO;2.

Shao, X. M., J. Harlin, M. Stock, M. Stanley, A. Regan, K. Wiens, T. Hamlin, M. Pongratz, D. Suszcynsky, and T. Light (2005), Katrina and Rita were 
lit up with lightning, Eos Trans. $A G U, 86(42), 398$, doi:10.1029 2005EO420004.

Solorzano, N. N., J. N. Thomas, and R. H. Holzworth (2008), Global studies of tropical cyclones using the World Wide Lightning Location Network, paper presented at Third Conference on Meteorological Application of Lightning Data, Am. Meteorol. Soc., New Orleans, La.

Squires, K., and S. Businger (2008), The morphology of eyewall lightning outbreaks in two category 5 hurricanes, Mon. Weather Rev., 136, 17061726, doi:10.1175/2007MWR2150.1.

Taranenko, Y., U. Inan, and T. Bell (1993a), The interaction with the lower ionosphere of electromagnetic pulses from lightning: Excitation of optical emissions, Geophys. Res. Lett., 20(23), 2675-2678, doi:10.1029/ 93GL02838.

Taranenko, Y., U. Inan, and T. Bell (1993b), Interaction with the lower ionosphere of electromagnetic pulses from lightning: Heating, attachment, and ionization, Geophys. Res. Lett., 20(15), 1539-1542, doi:10.1029/ 93GL01696.
Willoughby, H. E. (1988), The dynamics of the tropical cyclone core, Aust. Meteorol. Mag., 36, 183-191.

Zipser, E. J., D. J. Cecil, C. Liu, S. W. Nesbitt, and D. P. Yorty (2006), Where are the most intense thunderstorms on Earth?, Bull. Am. Meteorol. Soc., 87, 1057-1071, doi:10.1175/BAMS-87-8-1057.

S. A. Cummer, Department of Electrical and Computer Engineering, Duke University, PO Box 90291, Durham, NC 27708, USA. (cummer@ ee.duke.edu)

R. H. Holzworth, Department of Earth and Space Sciences, University of Washington, Johnson Hall Rm-070, Box 351310, 4000 15th Ave. NE, Seattle, WA 98195-1310, USA. (bobholz@ess.washington.edu)

N. N. Solorzano and J. N. Thomas, Physics Department, Bard High School Early College Queens, 30-20 Thomson Ave., 6th Floor, Long Island City, NY 11101,USA. (nataliansolo@gmail.com; jnt@u. washington.edu) 